\title{
Guillain-Barré Syndrome in a Case of Acute Lymphoblastic Leukaemia
}

\author{
A Case Report \\ Periasamy Vembu a Asmahan Al-Shubailia Adnan Al-Khuraibet ${ }^{a}$ \\ Olivia Kreze $^{b}$ Ramesh Panditab
}

albn Sina Hospital and ${ }^{b} K u w a i t$ Cancer Control Centre, Kuwait

\author{
Key Words \\ Guillain-Barré syndrome · Intravenous \\ immunoglobulins . United Kingdom Acute \\ Lymphoblastic Leukaemia-12 protocol · Chronic \\ lymphocytic leukaemia
}

syndrome and leukaemia rather than vincristine neurotoxicity. IVIG was an effective and non-invasive treatment for Guillain-Barré syndrome associated with the malignancy.

Copyright $@ 2003$ S. Karger AG, Basel

\begin{abstract}
Objective: To report a case of severe Guillain-Barré syndrome in a 32-year old female patient diagnosed with acute lymphoblastic leukaemia who was on chemotherapy. Clinical Presentation and Intervention: The patient received chemotherapy including vincristine and steroids according to the Medical Research Council United Kingdom Acute Lymphoblastic Leukaemia-12 (MRC UKALL-12) protocol. On the 21st day of the first induction course she developed acute fulminant quadriparesis with total areflexia. The clinical features, nerve conduction and the cerebrospinal fluid studies were consistent with acute Guillain-Barré syndrome. She was treated with a 5-day course of intravenous immunoglobulins (IVIG) that resulted in only partial improvement. A second course of IVIG was given 2 weeks later that improved her condition slowly and steadily over a period of 12-16 weeks; the patient was able to walk with minimal support. Conclusion: The fulminant neuropathy was most likely due to the association between Guillain-Barré
\end{abstract}

\section{Introduction}

Guillain-Barré syndrome (GBS) often follows infections with Campylobacter jejuni, herpes viruses, EpsteinBarr virus or cytomegalovirus. It has also been reported in association with malignancies including lymphoma, small cell lung cancer and leukaemia as well as their treatment [1]. The occurrence of a fulminant peripheral neuropathy with severe motor impairment mimicking acute GBS, following low doses of vincristine therapy in acute lymphoblastic leukaemia, is extremely rare [2]. However, fulminant neuropathy with severe motor involvement in association with vincristine therapy has been reported in patients with underlying Charcot-Marie-Tooth disease type 1A [3]. There are few reports on GBS occurring as a complication of acute lymphoblastic leukaemia treated with vincristine therapy [4]. We report herein a case of severe GBS in a 32-year-old female patient with acute lymphoblastic leukaemia.

\begin{tabular}{ll}
\hline KARGER & ( 2003 S. Karger AG, Basel \\
$1011-7571 / 03 / 0124-0272 \$ 19.50 / 0$ \\
$\begin{array}{l}\text { Fax +4161306 12 34 } \\
\text { E-Mail karger@karger.ch } \\
\text { www.karger.com }\end{array}$ & $\begin{array}{l}\text { Accessible online at: } \\
\text { www.karger.com/mpp }\end{array}$
\end{tabular}

Dr. V. Periasamy

Department of Neurology

Ibn Sina Hospital, PO Box 25427

13115 Safat (Kuwait)

Tel. +965 4840837, Fax +965 4849226, E-Mail thomas_tom@go.com 


\section{Case Report}

A 32-year-old woman, with no antecedent infectious illness and with an unremarkable past medical history, was diagnosed as a case of acute lymphoblastic leukaemia in 1999. She presented with pain in the right shoulder and spontaneous bruises. Physical examination showed ecchymotic spots, right axillary lymphadenopathy and splenomegaly. Examinations of chest, cardiovascular and central nervous systems were unremarkable. Investigations showed haemoglobin $12.8 \mathrm{~g} / \mathrm{dl}$, platelets $51 \times 10^{9} / 1$, and white blood cell count 35.8 $\times 10^{9} / 1$ with $85 \%$ blast cells. Bone marrow aspiration showed $85.4 \%$ blast cells (fig. 1) that were para-aminosalicylic acid-positive; Sudan black B-, peroxidase- and acid phosphatase-negative. Immunophenotypically, the blasts were CD10+, CD19+, CD45+, CD34+ and HLA-DR+. Myeloid and T-cell markers were negative.

The patient was started on induction chemotherapy according to the Medical Research Council United Kingdom Acute Lymphoblastic Leukaemia-12 (MRC UKALL-12) protocol, consisting of daunorubicin $100 \mathrm{mg}$ and vincristine $2 \mathrm{mg}$ given intravenously on days 1 , 8,15 and 22 , prednisolone $100 \mathrm{mg}$, once daily on days $1-28$, and $L$-asparaginase 10,000 units intramuscularly on days 17-28.

On day 21 of the first induction course, she developed distal paraesthesiae of four limbs, acute fulminant quadriparesis with total areflexia, bilateral foot drop, and bilateral facial weakness. Her nerve conduction studies showed signs of severe peripheral neuropathy, axonal demyelination because of marked slowing of motor conduction velocity, marked prolongation of motor terminal latencies, and proximal conduction block in all examined nerves (table 1). Day 21 bone marrow cytology revealed $15 \%$ blast cells. Her clinical features, nerve conduction studies, and classical albuminocytological dissociation of the cerebrospinal fluid were consistent with acute GBS (tables 1,2).

She was treated with a course of intravenous immunoglobulins (IVIG) $0.4 \mathrm{~g} / \mathrm{kg}$ body weigth daily for 5 days that resulted in only partial improvement necessitating administration of a second

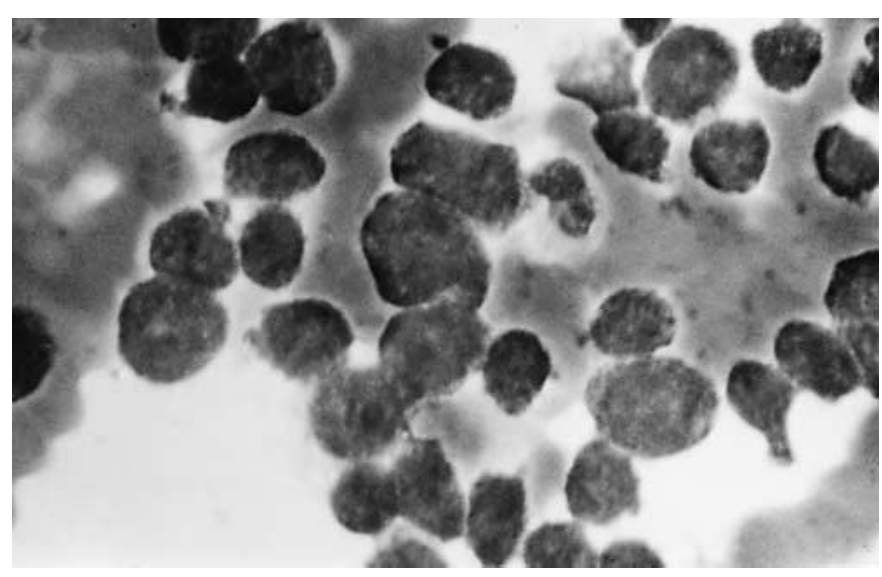

Fig. 1. Bone marrow smear showing lymphoblasts. Leishman stain. $\times 1,000$.

Table 1. Serial nerve conduction studies

\begin{tabular}{llcclll}
\hline $\begin{array}{l}\text { Duration } \\
\text { of illness }\end{array}$ & $\begin{array}{l}\text { Nerves } \\
\text { tested }\end{array}$ & $\begin{array}{l}\text { MCV } \\
\mathrm{m} / \mathrm{s}\end{array}$ & $\begin{array}{l}\mathrm{DML} \\
\mathrm{ms}\end{array}$ & $\begin{array}{l}\text { 'F' wave } \\
\mathrm{ms}\end{array}$ & $\begin{array}{l}\text { CMAP } \\
\mathrm{mV}\end{array}$ & Comment \\
\hline 3rd week & right peroneal & - & - & - & - & no CMAP \\
& $\begin{array}{l}\text { right sural } \\
\text { left median (M) }\end{array}$ & - & - & - & - & no SNAP \\
& left median (S) & - & - & - & - & no SNAP \\
\hline 6th week & right peroneal & - & - & - & - & no CMAP \\
& right sural & - & - & - & - & no SNAP \\
& right median (M) & 18 & 14.7 & absent & $0.4 / 0.2$ & \\
& right median (S) & - & - & - & - & no SNAP \\
\hline 8th week & right peroneal & - & - & - & - & no CMAP \\
& right sural & - & - & - & - & no SNAP \\
& right median (M) & 31 & 14.5 & absent & $0.4 / 0.2$ & \\
& right median (S) & - & - & - & - & no SNAP \\
\hline 16th week & right peroneal & - & - & - & - & no CMAP \\
& right sural & - & - & - & - & no SNAP \\
& right median (M) & 17 & 14.2 & absent & $0.6 / 0.4$ & \\
& right ulnar (M) & 27 & 9.2 & absent & $0.5 / 0.3$ & \\
& right median (S) & - & - & - & - & no SNAP \\
& & & & & & \\
\end{tabular}

$\mathrm{MCV}=$ Motor conduction velocity $(\mathrm{m} / \mathrm{s}) ; \mathrm{DML}=$ distal motor latency $(\mathrm{ms}) ; \mathrm{CMAP}=$ compound muscle action potential; SNAP = sensory nerve action potential; $\mathrm{M}=$ motor; $\mathrm{S}=$ sensory. Normal values: peroneal nerve (motor): $\geq 40 \mathrm{~m} / \mathrm{s}$; median and ulnar nerves (motor): $\geq 50 \mathrm{~m} / \mathrm{s}$; median nerve (sensory): $\geq 45 \mathrm{~m} / \mathrm{s}$; sural nerve: $\geq 40 \mathrm{~m} / \mathrm{s}$. 
Table 2. Lumbar puncture and cerebrospinal fluid (CSF) studies showed albuminocytological dissociation

\begin{tabular}{lllll}
\hline $\begin{array}{l}\text { Duration } \\
\text { of illness }\end{array}$ & $\begin{array}{l}\text { CSF } \\
\text { cells }\end{array}$ & $\begin{array}{l}\text { CSF } \\
\text { protein, mg/l }\end{array}$ & $\begin{array}{l}\text { CSF } \\
\text { sugar, mmol/l }\end{array}$ & $\begin{array}{l}\text { CSF } \\
\text { culture }\end{array}$ \\
\hline 1st week & no cells & 890 & 4.7 & negative \\
4th week & no cells & 796 & 3.4 & negative \\
6th week & no cells & 907 & 3.6 & negative \\
\hline
\end{tabular}

course. Following that, she improved slowly and steadily over a period of 12-16 weeks. She completed her full course of chemotherapy and was in remission, with minimal residual neurological deficits at the time of discharge. She had absent tendon jerks, moderate foot drop and minimal weakness (grade 4/5), but was able to walk with minimal support 16 weeks later.

\section{Discussion}

Neoplasms of immune system tissues may cause GBS in a manner similar to some viral infections [2]. However, the remote effects probably relate to transient immunosuppression caused by the disease, the chemotherapy or by both $[5,6]$. Our patient's neurologic syndrome, spinal fluid and electromyographic findings were consistent with GBS. It was important to know whether the GBS was related to either the underlying malignancy or chemotherapy, especially vincristine, in which case it would have implications on the type and dose of treatment.

There are few reports of GBS occurring as a complication of acute non-lymphoblastic leukaemia and chronic lymphocytic leukaemia treated with chemotherapy. Peripheral nerve complications of acute leukaemias are uncommon. The neuropathies are frequently related to haemorrhages into the nerves, infarction or leukaemic infiltration [5]. However, this type of neuropathies is focal or asymmetrical in distribution. The cerebrospinal fluid study of this patient did not reveal any leukaemic cells. Other possible mechanisms are reduced suppressor T-cell function and hypogammaglobulinaemia in leukaemia [57]. Banerjee et al. [8] described a patient, who presented with a symmetrical polyradiculopathy 6 months before the onset of acute lymphoblastic leukaemia. Moudgil et al. [2] reported a patient after diagnosis of acute lymphoblastic leukaemia with fulminant peripheral neuropathy and severe quadriparesis associated with vincristine therapy. Neurotoxicity in the form of peripheral neuropathy is a commonly recognized dose-limiting complication of vincristine chemotherapy.
The peripheral neuropathy associated with vincristine, however, is usually mild and manifests with distal sensory loss and loss of deep tendon reflexes, particularly loss of both ankle jerks $[2,9]$. GBS also very rarely presents with acute quadriparesis and cranial nerve involvement, resembling a locked-in (motionless) state, after vincristine therapy [10]. The occurrence of a fulminant peripheral neuropathy with severe motor impairment following low doses of vincristine therapy is distinctly rare and occurs most often in patients with underlying Charcot-Marie-Tooth disease [3]. There was no clinical evidence that our patient had Charcot-Marie-Tooth disease. Severe motor weakness and superficial sensory loss are less common in vincristine toxicity. Vincristine neuropathy produces prolonged distal latencies with preserved motor nerve conduction velocities due to damage to terminal nerve fibres. Proximal nerve trunks are less affected and so the neuropathy is predominantly distal. It also produces reduced compound muscle action potentials and reduced amplitude of sensory nerve action potentials with preserved sensory nerve conduction velocity. Vincristine neurotoxicity is mostly related to the dose and duration of therapy [9].

In contrast to the above, our patient developed severe motor neuropathy, cranial nerve involvement, conduction block in several nerves examined for the reduced conduction velocities. With IVIG treatment, the patient improved within several weeks and tolerated a further course of vincristine therapy. It is not clear whether the GBS in this patient was primarily due to leukaemia or vincristine toxicity.

However, our data indicate that the fulminant neuropathy with severe motor deficit that occurred in this patient was most likely due to leukaemia-associated GBS rather than vincristine neurotoxicity. It is also worth noting that despite the severity of motor weakness, it was possible to achieve a good therapeutic response with two courses of IVIG rather than a more invasive approach using plasmapheresis.

\section{Conclusion}

Our findings indicate that the fulminant neuropathy with severe motor deficit that occurred in this patient was most likely due to leukaemia-associated GBS rather than vincristine neurotoxicity. IVIG was an effective and noninvasive treatment for GBS associated with this malignancy. We recommend that leukaemia should be considered as the preceding illness before the onset of GBS when the aetiology is not clear. 


\section{References}

1 Phan TG, Hersch M, Zagami AS: GuillainBarré syndrome and adenocarcinoma of the gall bladder: A paraneoplastic phenomenon? Muscle Nerve 1999;22:141-142.

2 Moudgil SS, Riggs JE: Fulminant peripheral neuropathy with severe quadriparesis associated with vincristine therapy. Ann Pharmacother 2000;34:1136-1138.

3 Graf WD, Chance PF, Lensch MW, Eng LJ, Lipe HP, Bird TD: Severe vincristine neuropathy in Charcot-Marie-Tooth disease type 1A Cancer 1996;77:1356-1362.
4 Norman M, Elinder G, Finkel Y: Vincristine neuropathy and a Guillain-Barré syndrome: A case with acute lymphatic leukaemia and quadriparesis. Eur J Haematol 1987;39:75-76.

5 Rodrigues A, Monteiro J, Viana J, Macedo A, Graca F, Sena A: Acute non-lymphoblastic leukaemia presenting as Guillain-Barré syndrome. J Neurol Neurosurg Psychiatry 1993;56:936937.

6 Jackson M: Guillain-Barré syndrome in a patient with chronic lymphocytic leukaemia. Postgrad Med J 1993;69:832-834.

7 Geetha N, Hussain BM, Lali VS, Nair MK, Kumar BS: Guillain-Barré syndrome occurring as a complication of acute nonlymphoblastic leukemia. Am J Med 1999;107:100-101.
8 Banerjee P, MacCallum PK, Walker RW, Lister TA: Polyradiculopathy complicating acute lymphoblastic leukemia. Hematol Oncol 1995; 13:45-47.

9 Pal PK: Clinical and electrophysiological studies in vincristine-induced neuropathy. Electromyogr Clin Neurophysiol 1999;39:323-330.

10 Bakshi N, Maselli RA, Gospe SM Jr, Ellis WG McDonald C, Mandler RN: Fulminant demyelinating neuropathy mimicking cerebral death. Muscle Nerve 1997;20:1595-1597. 